\title{
RÂNULA: RELATO DE UM CASO COM INTENSA SINTOMATOLOGIA
}

Gabriel Leonardo MAGRIN, Mário HARA JÚNIOR, Cassius TORRES

Rânulas são lesões no assoalho bucal associados às glândulas salivares maiores caracterizadas por ausência de sintomatologia na quase totalidade dos casos. A proposição desse trabalho é descrever um caso de rânula não convencional, devido à grande dimensão assumida, à sintomatologia aguda, e as proposições terapêuticas adotadas. Paciente de 25 anos, sexo feminino, procurou a Disciplina de Estomatologia da UFPR queixando-se de uma lesão bolhosa que surgiu havia aproximadamente três meses em assoalho bucal e que, nos três dias anteriores à consulta, Ihe causava dor intensa. Ao exame extra-bucal notou-se edema submandibular e deslocamento da língua. No exame intra-bucal observou-se lesão bolhosa em assoalho bucal, única, com aproximadamente seis centímetros em sua maior extensão, forma de cúpula e superfície lisa. O diagnóstico clínico foi caracterizado como fenômeno obstrutivo compatível com rânula. A abordagem terapêutica adotada foi a marsupialização do teto da bolha sob anestesia local, permitindo o extravasamento do muco. Após 14 dias, a paciente apresentava funções normais e ausência de sintomatologia. A rânula possui diagnóstico eminentemente clínico. Seu tratamento, porém, pode requerer abordagens pouco usuais. A marsupialização mostrou-se uma técnica eficiente e pouco invasiva no presente caso.

Palavras-chave: Ductos Salivares; Doenças Bucais; Doenças da Glândula Submandibular; Doenças das Glândulas Salivares; Dor Facial. 